\title{
Glycerol-plasticized bacterial nanocellulose-based composites with enhanced flexibility and liquid sorption capacity
}

\author{
Izabela Cielecka (D) Marcin Szustak - Halina Kalinowska - Edyta Gendaszewska-Darmach • \\ Małgorzata Ryngajłło - Waldemar Maniukiewicz - Stanisław Bielecki
}

Received: 9 January 2019/Accepted: 9 May 2019/Published online: 16 May 2019

(C) The Author(s) 2019

\begin{abstract}
Bacterial nanocellulose (BNC) and two BNC-based composites with carboxymethyl cellulose or hydroxyethyl cellulose (BNC-CMC or BNC-HEC, respectively), were produced in situ by Komagataeibacter xylinus E25 under stationary conditions and plasticized with glycerol (ex situ modification). The BNC-CMC composite had the loosest structure (visible in SEM images) and was less crystalline (CI of $88.6 \%$ ) than BNC (CI of 92.9\%) and BNC-HEC (CI of $90.4 \%$ ). Cellulose fibers synthesized by K. xylinus E25 in the presence of HEC were thinner in comparison to the fibers of control $\mathrm{BNC}$ while there was no difference in the fibers width between the BNC$\mathrm{CMC}$ and control BNC. The glycerol-plasticized BNC, BNC-CMC and BNC-HEC membranes were flexible after drying, and absorbed high amounts of artificial exudate and water after rehydration. BNCCMC treated with $2.5 \% \mathrm{v} / \mathrm{v}$ aqueous glycerol was characterized by the greatest free swell absorptive capacity (up to $19 \mathrm{~g}$ artificial exudate/g dry weight in $24 \mathrm{~h}$ ) while the highest rehydration capacity (around $96 \%$ of the initial water content) was observed in case
\end{abstract}

I. Cielecka $(\bowtie) \cdot$ M. Szustak · H. Kalinowska •

E. Gendaszewska-Darmach · M. Ryngajłło - S. Bielecki Institute of Technical Biochemistry, Lodz University of Technology, Lodz, Poland

e-mail: izabela.cielecka@edu.p.lodz.pl

W. Maniukiewicz

Institute of General and Ecological Chemistry, Lodz

University of Technology, Lodz, Poland of BNC-CMC plasticized with $10 \% \mathrm{v} / \mathrm{v}$ glycerol and dehydrated. The in situ and ex situ modifications of BNC affected also the tensile strength. The highest values of tensile strength at break (around 152.2 N) and Young's modulus (around 290.3 MPa) were observed in case of the BNC-CMC composite plasticized with $2.5 \% \mathrm{v} / \mathrm{v}$ glycerol. The impact of plasticized BNC, BNC-CMC and BNC-HEC on the viability of $\mathrm{HaCaT}$ keratinocytes was also studied and found to be positive at glycerol concentrations up to $2.5 \%(\mathrm{v} / \mathrm{v})$ that suggests their potential utility as wound dressings.

Keywords Bacterial nanocellulose Composite . Wound dressing $\cdot$ Liquid sorption capacity

\section{Introduction}

Bacterial nanocellulose (BNC) is a natural, nontoxic, biocompatible and mechanically durable gelatinous polymer with high water-holding capacity, which has proven to be an excellent wound dressing and found numerous potential applications not only in medicine (Campano et al. 2016; Ullah et al. 2016). Its most efficient producers are non-pathogenic, Gram-negative, rod shaped and strictly aerobic bacteria of the Komagataeibacter genus that assimilate various sugars and other compounds as carbon source. Cells of Komagataeibacter species extrude cellulose chains 
through multiple pores (around 50 per cell) that are located in the cytoplasmic membrane in a row along the longitudinal axis, and produce $70-150 \mathrm{~nm}$ wide ribbons composed of 10-100 hydrogen-bonded cellulose microfibrils (Bielecki et al. 2002). The polymerization of uridine diphosphate glucose (UDP-glucose), mediated by cellulose synthase, is coupled with formation of the highly crystalline (above 60\%) nanocellulose structure, maintained by the threedimensional network of multiple intra- and intermolecular hydrogen bonds (Bielecki et al. 2002). Examples of media that are used for cultivation of BNC producers include the Schramm-Hestrin (SH) medium, natural media like coconut water (Budhiono et al. 1999) or coconut milk (Nakagaito et al. 2005) and media based on various low-cost feedstocks, including by-products from food processing (Machado et al. 2018; Velasquez-Riano and Bojaca 2017).

One of attractive BNC properties is the chemical purity, what makes it suitable for various modifications. The polymer may be modified either in situ during biosynthesis by bacteria or ex situ after BNC harvesting. Diverse cellulose-based nanocomposites obtained by either in situ and/or ex situ methods could found numerous applications in medicine (Taokaew et al. 2015; Ullah et al. 2016) and other fields (Campano et al. 2016). In case of the in situ approach, changes in the structure of BNC may be achieved, among others, by supplementation of culture media with various polysaccharides and other polymers. The first polysaccharide studied was carboxymethylcellulose (CMC), which was found to delay the aggregation of cellulose molecules (Ben-Hayyim and Ohad 1965). Other examples of polymers which can form hydrogen bonds with cellulose chains and this way reduce the strength of noncovalent interactions between cellulose microfibrils and alter the assembly pattern of BNC fibres are polysaccharides like pectin, sodium alginate, chitin, agar (Dayal and Catchmark 2016), K-carrageenan (Cielecka et al. 2018), hyaluronic acid ( $\mathrm{Li}$ et al. 2015), hydroxyethylcellulose (Zhou et al. 2009), exopolysaccharides from Escherichia coli (Liu and Catchmark 2018), water soluble exopolysaccharides from Gluconacetobacter xylinus (Fang and Catchmark 2014), and hemicelluloses (Uhlin et al.1995). Also Aloe vera gel pulp, gel extract and polysaccharide fraction (Godinho et al. 2016), poly(ethylene glycol) (Hessler and Klemm 2009) and gelatin (Chen et al.
2014) have the similar impact. The noncovalent binding of aforementioned polymers to cellulose affects the crystal size, crystallinity, porosity and water holding capacity of the biosynthesized product. Apart from the in situ modifications, also a variety of ex situ methods are used to obtain novel BNC-based materials for medicine and cell cultures, e.g. modification with dextran (Lin et al. 2017), organosilanes (Taokaew et al. 2015) or plasticizers like poly(ethylene glycol) (Cai and Kim 2010).

In this study, BNC-based nanocomposites obtained by combination of the in situ and ex situ modifications were characterized and their effect on the viability of keratinocytes was studied. BNC was modified in situ using either CMC or HEC. Then, the native BNC (the control), BNC-CMC and BNC-HEC membranes, produced by $K$. xylinus E25 under stationary conditions, were plasticized with $0.5-10 \% \mathrm{v} / \mathrm{v}$ aqueous glycerol solutions. This polyol is one of popular, natural, renewable and biodegradable plasticizers (Vieira et al. 2011). Glycerol used as a plasticizer of bacterial cellulose, causes a decrease in the strength of intermolecular hydrogen bonds between adjacent cellulose chains. That results in improvement of the flexibility of pellicles and prevention of formation of rigid and brittle BNC sheets after dehydration (Sun et al. 2018). Furthermore, glycerol-plasticized BNC becomes more transparent, which is also advantageous. The transparency of BNC-based wound dressings facilitates monitoring of wound healing process while the increased hydration and flexibility enable easy and painless application and removal of wound coverings (Bielecki et al. 2013). Glycerol is not only a widely applied plasticizer but also a component of many moisturizing cosmetics and therefore, its contact with skin is permitted. The outermost layer of the skin, exposed to the contact with wound dressings is the epidermis, and the predominant cell type in the epidermis is keratinocyte (MacNeil 2007). Therefore, to assess potential effect of the long-term contact of glycerol-plasticized BNC-based wound dressings we decided to determine the impact of glycerol concentration in the wound dressing on the viability of keratinocytes. Bacterial cellulose films are known to support the growth, spreading and migration of human keratinocytes (Sanchavanakit et al. 2006). However, the occurrance of CMC or HEC in the BNC-based nanocomposites may either positively or negatively affect these cells. Therefore, the final objective of this 
study was to determine the impact of BNC modification with water soluble polysaccharides and glycerol on the viability of keratinocytes, using the immortal human keratinocyte HaCaT cell line as a model.

\section{Materials and methods}

Microbial strain

Komagataeibacter xylinus E25 strain used in this study was obtained from the culture collection of the Institute of Technical Biochemistry (Lodz University of Technology). The strain belongs to BOWIL Biotech Ltd., Poland.

Culture media

K. xylinus E25 strain was cultivated under stationary conditions in the Schramm-Hestrin (SH) medium containing glucose $(20 \mathrm{~g} / \mathrm{L})$, yeast extract $(5.0 \mathrm{~g} / \mathrm{L})$, peptone $(5.0 \mathrm{~g} / \mathrm{L}), \mathrm{MgSO}_{4} \times 7 \mathrm{H}_{2} \mathrm{O}(0.5 \mathrm{~g} / \mathrm{L})$, anhydrous $\mathrm{Na}_{2} \mathrm{HPO}_{4}(2.7 \mathrm{~g} / \mathrm{L})$ and citric acid $(1.15 \mathrm{~g} / \mathrm{L})$, dissolved in distilled water. The $\mathrm{pH}$ of the culture medium was adjusted to 5.7 using $0.1 \mathrm{M}$ acetic acid. To produce the BNC-CMC and BNC-HEC composites, the SH medium was supplemented with either $0.5 \%$ carboxymethyl cellulose (CMC) or $0.5 \%$ hydroxyethyl cellulose (HEC), respectively. Both CMC (Mw around 90,000, degree of substitution of 0.7) and HEC (Mw around 90,000, degree of substitution of 0.6) were purchased from Sigma-Aldrich.

Biosynthesis and purification of BNC, BNC-CMC and BNC-HEC

K. xylinus E25 was activated by cultivation under stationary conditions in the Schramm-Hestrin (SH) medium (supplemented with $1 \% \mathrm{v} / \mathrm{v}$ ethanol before inoculation) at $30{ }^{\circ} \mathrm{C}$ for 2 days and used as an inoculum. The SH medium, either without additives or supplemented with either $0.5 \%$ carboxymethyl cellulose (SH-CMC) or $0.5 \%$ hydroxyethyl cellulose (SHHEC), was supplemented with ethanol ( $1 \% \mathrm{v} / \mathrm{v})$ before the inoculation with bacterial pre-culture $(5 \% \mathrm{v} / \mathrm{v})$. $\mathrm{BNC}, \mathrm{BNC}-\mathrm{CMC}$ and BNC-HEC membranes were obtained after 7-day culture in stationary conditions at $30{ }^{\circ} \mathrm{C}$.
Purification of all the membranes included rinsing with tap water until flushing out of the remaining medium, $24 \mathrm{~h}$ washing with $1 \% \mathrm{w} / \mathrm{v}$ sodium hydroxide for bacterial cells removal, and subsequent immersing in $1 \% \mathrm{v} / \mathrm{v}$ acetic acid and then distilled water for $\mathrm{pH}$ neutralization. Purified membranes were packed, sterilized by autoclaving at $121^{\circ} \mathrm{C}$ and stored at $4{ }^{\circ} \mathrm{C}$ before further analytical steps.

Preparation of composites with glycerol

Never-dried BNC, BNC-CMC and BNC-HEC membranes with a diameter of $38 \mathrm{~mm}$ were immersed in $300 \mathrm{~mL}$ aliquots of aqueous glycerol solutions with concentrations ranging from 0.1 to $10 \%$. Glycerol (for molecular biology) was purchased from SigmaAldrich. The incubation was conducted for $24 \mathrm{~h}$ at $80 \mathrm{rpm}$ and $20-22{ }^{\circ} \mathrm{C}$. Then the plasticized membranes were dried at $80{ }^{\circ} \mathrm{C}$ for $24 \mathrm{~h}$ until constant mass was achieved. An excess of aqueous glycerol solution was used to minimize the dilution caused by the occurrence of water inside the never-dried membranes. The calculations showed that in the experimental conditions the decrease in glycerol concentration was relatively small, e.g. from 10 to $9.8 \% \mathrm{v} / \mathrm{v}$. Next, the samples were sterilized and stored at $4{ }^{\circ} \mathrm{C}$ before use.

Characterization of BNC, BNC-CMC and BNCHEC

\section{Scanning electron microscopy}

Scanning electron microscopy was applied for visualization of BNC, BNC-CMC and BNC-HEC fibres in nanocomposites. Samples of the membranes were freeze-dried and afterwards, sputter coated with gold layer and observed using a FEI QUANTA 250 FEG microscope (Thermo Fischer Scientific, MA, USA) (HV $2 \mathrm{kV}$, magnification $40000 \times$ ). Fibres thickness was measured using the Makroaufmassprogramm software on the basis on SEM images. The probability density functions were drown using the R (v. 3.4.1) software. 
Fourier transform infrared spectrometry

in an attenuated total reflectance mode analysis

The incorporation of either CMC or HEC into BNC membranes was evaluated with the FTIR-ATR using a Nicolet 6700 FT-IR (Thermo Scientific, MA, USA). The spectra of BNC, BNC-CMC, BNC-HEC, CMC and HEC were recorded over the range from 4000 to $650 \mathrm{~cm}^{-1}$ and 200 scans were accumulated, with a spectral resolution of $4 \mathrm{~cm}^{-1}$.

\section{$X$-ray diffractometry}

Room temperature powder X-ray diffraction patterns were collected using a PANalytical X'Pert Pro MPD diffractometer (Malvern Panalytical Ltd, UK) with the Bragg-Brentano reflection geometry and the graphite monochromated $\mathrm{Cu}-\mathrm{K} \alpha$ radiation. It was equipped with a PANalytical X'Celerator detector. Samples were scanned in the $2 \theta$ range between $5^{\circ}$ and $60^{\circ}$. The scan speed was $30 \mathrm{~s}$ per step of $0.0167^{\circ}$. The samples were spun during data collection to minimize preferred orientation effects. X-ray diffraction patterns were resolved into a broad amorphous halo and five crystalline peaks using WAXFIT program (Rabiej 2014). The crystallinity index was calculated as the ratio of the integral intensity under all crystalline peaks to the sum of integral intensity under the crystalline peaks and amorphous halo (Park et al. 2010).

Characterization of $\mathrm{BNC}, \mathrm{BNC}-\mathrm{CMC}$ and $\mathrm{BNC}-$

HEC composites with glycerol

\section{Free swell absorptive capacity}

The dependence of liquid absorption properties of BNC, BNC-CMC and BNC-HEC membranes on glycerol concentration was determined according to the modified ISO 13726 standard. The plasticized membranes with diameter of $38 \mathrm{~mm}$ (dried at $80{ }^{\circ} \mathrm{C}$ for $24 \mathrm{~h}$ until constant weight) were immersed in artificial exudates (solution of $8.298 \mathrm{~g}$ of sodium chloride and $0.368 \mathrm{~g}$ of anhydrous calcium chloride in $1 \mathrm{~L}$ of deionised water) at $37{ }^{\circ} \mathrm{C}$ for $30 \mathrm{~min}$ and $24 \mathrm{~h}$. Then the excess of the artificial exudates was removed with filter paper, and the swollen membranes were weighted $\left(\mathrm{W}_{\mathrm{W}}\right)$. Free swell absorptive capacity values were calculated from the Eq. 1, and expressed as grams of artificial exudates absorbed by $1 \mathrm{~g}$ of composite dry weight $\left(\mathrm{W}_{\mathrm{D}}\right)$.

Absorptive capacity $=\frac{W_{W}}{W_{D}}$

The experiment was carried out in triplicate for each BNC-based composite.

\section{Rehydration capacity of dehydrated plasticized membranes}

After plasticization with the aqueous glycerol solutions (at glycerol concentrations ranging between 0.1 and $10 \% \mathrm{v} / \mathrm{v}$, as described in the section Preparation of composites with glycerol, the membranes (diameter of $38 \mathrm{~mm}$ ) were weighted ( $\left.\mathrm{W}_{\mathrm{W} 1}\right)$ and next, dehydrated at $80{ }^{\circ} \mathrm{C}$ until constant weight $\left(\mathrm{W}_{\mathrm{D}}\right)$. To determine the rehydration capacity, the membranes were immersed in distilled water for $24 \mathrm{~h}$ to achieve the swollen state. Then the water excess on the surface was removed with filter paper, and the wet membranes were weighted $\left(\mathrm{W}_{\mathrm{W} 2}\right)$. The rehydration capacity $\left(\mathrm{R}_{\mathrm{C}}\right)$ was calculated from the Eq. (2) after $30 \mathrm{~min}$ and $24 \mathrm{~h}$.

$R_{C}=\frac{W_{W 2}-W_{D}}{W_{W 1}-W_{D}} \cdot 100 \%$

All the measurements were performed in triplicate.

\section{Tensile test}

Before characterization of tensile strength, BNC, BNC-CMC and BNC-HEC membranes $(9 \mathrm{~cm} \times 15 \mathrm{~cm})$ were gently wiped with filter paper and immersed for $24 \mathrm{~h}$ at $80 \mathrm{rpm}$ and $20-22{ }^{\circ} \mathrm{C}$ in $300 \mathrm{~mL}$ of either $2.5 \%$ or $10 \%$ (v/v) aqueous glycerol solution. The concentration of $2.5 \% \mathrm{v} / \mathrm{v}$ was selected because it corresponded to the highest free swell absorptive capacity of all the nanocomposites while the concentration of $10.0 \% \mathrm{v} / \mathrm{v}$ was the highest glycerol concentration studied in this work. Besides, the results of this study showed that the latter glycerol concentration corresponded to the highest rehydration capacity and high free swell absorption capacity, which are attractive in case of wound dressings. This procedure was repeated 3 times to minimize the dilution of glycerol solution caused by the presence of residual water in the never-dried membranes.

The BNC, BNC-CMC and BNC-HEC membranes, either treated with 2.5 and $10 \% \mathrm{v} / \mathrm{v}$ glycerol or not, 
were examined for tensile strength using a universal testing machine (Zwick/Roell Z1.0, Germany) according to (Cielecka et al. 2018). Before the tensile tests, an excess of water attached to BNC and BNC-based nanocomposites was removed by pressing until $1 \mathrm{~mm}$ thickness was achieved. The composites plasticized with glycerol were dehydrated at $80{ }^{\circ} \mathrm{C}$ until constant weight was achieved.

The maximum stress and elongation at break were estimated using the TestXpert ${ }^{\circledR}$ II software. Stress $(\sigma)$ was calculated as F/A, where $\mathrm{F}$ is the loading force, expressed in Newtons $(\mathrm{N})$, and $\mathrm{A}$ is the cross-section area measured as the width $\times$ thickness of a sample. Strain $(\varepsilon)$ was calculated as $\Delta \mathrm{L} / \mathrm{L}_{0} \times 100 \%$, where $\mathrm{L}_{0}$ is the initial length and $\Delta \mathrm{L}$ is the exerted extension from starting point. Values of the Young's modulus under tension were calculated from the stress/strain relationship in the first linear region of the graph. The measurements were performed in 5 replicates.

\section{Keratinocytes viability study}

\section{Human keratinocyte cell line HaCaT}

The immortal human keratinocyte $\mathrm{HaCaT}$ cell line was purchased from Leibniz Institute DSMZ - German Collection of Microorganisms and Cell Cultures (Braunschweig, Germany). The cells were cultured in Dulbecco's modified Eagle's medium (DMEM) supplemented with $10 \%$ fetal bovine serum (FBS) containing $100 \mathrm{IU} / \mathrm{mL}$ penicillin, $100 \mu \mathrm{g} / \mathrm{mL}$ neomycin and $2.5 \mu \mathrm{g} / \mathrm{mL}$ amphotericin B. All reagents for cell culture were obtained from the Life Technologies (Carlsbad, CA, USA). The cells were incubated at $37{ }^{\circ} \mathrm{C}$ in a humidified atmosphere supplemented with $5 \% \mathrm{CO}_{2}$.

\section{Scaffold preparation}

Wet BNC, BNC-CMC and BNC-HEC scaffolds (16 $\mathrm{mm}$ in diameter) were plasticized with either $2.5 \% \mathrm{v} / \mathrm{v}$ or $10 \% \mathrm{v} / \mathrm{v}$ glycerol for $24 \mathrm{~h}$, and then dehydrated. The concentration of $2.5 \% \mathrm{v} / \mathrm{v}$ was selected because it corresponded to the highest free swell absorptive capacity of all the nanocomposites while the concentration of $10.0 \% \mathrm{v} / \mathrm{v}$, being the highest glycerol concentration studied in this work, corresponded to the highest rehydration capacity. After dehydration, the scaffolds were transferred to a
24 well plate, and $500 \mu \mathrm{L}$ aliquots of the growth medium (DMEM/FBS) were added to each well before the seeding of the HaCaT cells. The soaked scaffolds were used to determine the surface growth viability or viability of cells growing under scaffolds as described below. The control scaffolds without glycerol were prepared analogously.

\section{Extract exposure method}

Extracts were obtained by immersing BNC, BNCCMC, BNC-HEC membranes plasticized with $10 \%$ glycerol $\left(1.9 \mathrm{~cm}^{2} / 0.5 \mathrm{~mL}\right)$ in the growth medium (DMEM/FBS) at $37{ }^{\circ} \mathrm{C}$ for $24 \mathrm{~h}$. Aliquots of each extract were collected and used to prepare 2 mixtures with the DMEM culture medium, containing either $50 \%(50 \mu \mathrm{L}$ of extract were mixed with $50 \mu \mathrm{L}$ of DMEM culture medium) or $25 \%(25 \mu \mathrm{L}$ of extract were mixed with $75 \mu \mathrm{L}$ of DMEM culture medium) of the extract. The third variant of extract medium contained $100 \%$ extract. Before the exposure to the extract and its mixtures with the DMEM culture medium, HaCaT cells were plated in 96-well plates and grown to subconfluency. Then, the culture medium was removed and replaced with the extract media, and the cells were incubated for $24 \mathrm{~h}$ at $37{ }^{\circ} \mathrm{C}$ in a humidified atmosphere. At the end of incubation, $8 \mu \mathrm{l}$ aliquots of PrestoBlue cell viability reagent (Life Technologies, Van Allen Way, CA, USA), being a resazurin-based solution, were added into each well and the mixtures were further incubated for $60 \mathrm{~min}$ at $37{ }^{\circ} \mathrm{C}$ and $5 \% \mathrm{CO}_{2}$. Cell viability was determined by measuring the fluorescent signal F530/590 on a Synergy 2 Microplate Reader (Bio-Rad, CA, USA). The obtained fluorescence magnitudes were used to calculate cell viability expressed as a percent of the viability of the untreated control cells.

\section{Glycerol cytotoxicity}

The HaCaT cells were seeded into 96 -well plates $\left(10^{4}\right.$ cells per well, suspended in $100 \mu \mathrm{L}$ of the growth medium). After $24 \mathrm{~h}$ incubation, the growth medium was replaced with $100 \mu \mathrm{L}$ medium supplemented with $0.5,1.0,2.5,5.0$ and $10.0 \%$ v/v glycerol. Afterwards, 8 $\mu \mathrm{L}$ aliquots of PrestoBlue cell viability reagent (Life Technologies, Van Allen Way, CA, USA), being a resazurin-based solution, were added into each well and the mixtures were further incubated for $60 \mathrm{~min}$ at 
$37{ }^{\circ} \mathrm{C}$ and $5 \% \mathrm{CO}_{2}$. Cell viability was determined by measuring the fluorescent signal F530/590 on a Synergy 2 Microplate Reader (Bio-Rad, CA, USA). The obtained fluorescence magnitudes were used to calculate the cell viability, which was expressed as a percent of the viability of the untreated control cells.

\section{Surface growth viability of $\mathrm{HaCaT}$ cells}

For the direct assay, the soaked scaffolds, either with or without glycerol were placed on a 24-well plate. Then $2 \times 10^{5} \mathrm{HaCaT}$ cells (suspended in $500 \mu \mathrm{L}$ growth medium) were seeded on the surface of the scaffolds. The cells were incubated at $37{ }^{\circ} \mathrm{C}$ in a humidified atmosphere for $24 \mathrm{~h}$. Then, $40 \mu \mathrm{L}$ aliquots of PrestoBlue cell viability reagent were added to each well and the mixtures were further incubated for $60 \mathrm{~min}$ at $37{ }^{\circ} \mathrm{C}$ and $5 \% \mathrm{CO}_{2}$. Next, $100 \mu \mathrm{L}$ aliquots of these mixtures were transferred to a 96-well plate to measure the fluorescent signal F530/590 of samples. The obtained fluorescence magnitudes were used to calculate the cell viability, which was expressed as a percent of the viability of the cells growing on the control commercial plastic scaffold (Eq. 3).

viability $[\%]=\frac{R F U_{\text {sample }}-R F U_{\text {medium }}}{R F U_{\text {control }}-R F U_{\text {medium }}} \cdot 100 \%$

\section{Viability of HaCaT cells growing under scaffolds}

$\mathrm{HaCaT}$ cells were seeded into 24-well plates in the number of $2 \times 10^{4}$ per well (suspended in $500 \mu \mathrm{L}$ growth medium). After $24 \mathrm{~h}$ incubation, the medium was removed and the cells were covered by the soaked scaffold and incubated under the scaffold for the next $24 \mathrm{~h}$. Then, the scaffolds were removed and $40 \mu \mathrm{l}$ aliquots of PrestoBlue ${ }^{\circledR}$ Cell Viability Reagent were added into each well and the mixtures were further incubated for $60 \mathrm{~min}$ at $37{ }^{\circ} \mathrm{C}$ and $5 \% \mathrm{CO}_{2}$. Then 100 $\mu \mathrm{L}$ aliquots of the mixtures were transferred to a 96-well plate to measure the fluorescent signal F530/ 590. The obtained fluorescence magnitudes were used to calculate cell viability expressed as a percent of the viability of the cells growing on the plastic surface (Eq. 3).
Statistical analysis

The data are presented as mean \pm SD from at least triplicate analyses. Statistical significance of data was evaluated by analysis of variance (ANOVA; $p<0.05$ ) using the GraphPad Prism 6 software. For significant effects in case of viability study the Bonferroni test was performed.

\section{Results and discussion}

Characterization of BNC, BNC-CMC and BNCHEC

\section{BNC-CMC and BNC-HEC biosynthesis yields}

The results of several independent cultures of $K$. xylinus E25 in the $\mathrm{SH}$ medium, either without additives or supplemented with either $0.5 \%$ carboxymethyl cellulose (CMC) or $0.5 \%$ hydroxyethyl cellulose (HEC), presented in Fig. 1, demonstrate that the yields of biosynthesis of BNC $(3.93 \pm 0.12 \mathrm{~g}$ d.w./L) and BNC-HEC (3.91 $\pm 0.01 \mathrm{~g}$ d.w./L) membranes were slightly greater compared to the BNCCMC (3.71 $\pm 0.04 \mathrm{~g} \mathrm{~d}$.w./L) ones. The lower yield of BNC-CMC biosynthesis (by around 5.6\% compared to $\mathrm{BNC}$ ) is contradictory to findings of other authors who reported the enhanced in situ production of many BNC-based composites, including BNC-CMC, compared to BNC (Cheng et al. 2009). According to the latter authors, supplementation of the culture medium with either $0.2 \%$ or $0.5 \% \mathrm{CMC}$ increased the yield of BNC from 1.34 to around 4.9 and $7.2 \mathrm{~g} / \mathrm{L}$, respectively. According to Zhou et al. (2009) the culture

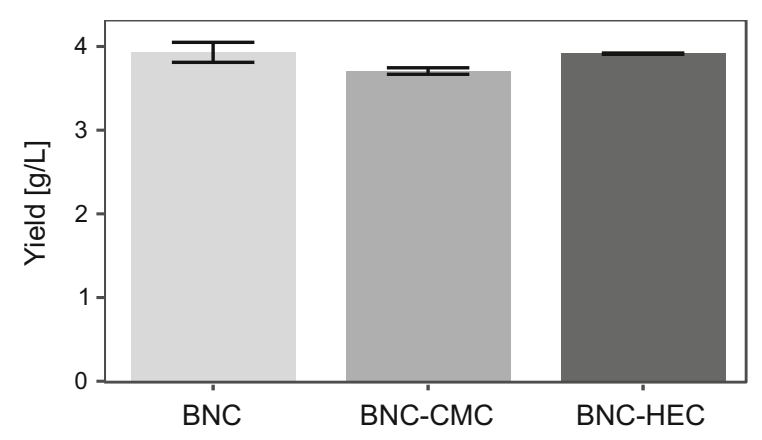

Fig. 1 The yields of BNC, BNC-CMC and BNC-HEC biosynthesis 
medium supplementation with HEC increased the yield of bacterial cellulose synthesis (e.g. to $128 \%$ and $190 \%$ for $0.5 \%$ and $4 \% \mathrm{w} / \mathrm{v}$ HEC, respectively). However, certain authors who studied the effect of various additives on BNC production have not mentioned their impact on BNC yield (Dayal and Catchmark 2016). The K. xylinus E25 strain used in this study produced nearly the same amounts of extracellular polymer in the presence and absence of the two soluble cellulose derivatives. Different yields of BNCbased composites produced in situ in culture media supplemented with CMC and HEC may be ascribed to differences in dynamics of BNC biosynthesis by various $K$. xylinus strains and diverse cultivation conditions.

Despite the weak effect of both CMC and HEC on the yield of the polymer produced by the K. xylinus E25 strain, further analyses showed that both BNCCMC and BNC-HEC composites differed from the control BNC in the structure, crystallinity and tensile strength.

\section{Morphology of BNC, BNC-CMC and BNC-HEC}

The SEM images, presented in Fig. 2a-c, demonstrate changes in the porous morphology of cellulose caused by incorporation of HEC and CMC. The BNC-CMC composite had the loosest structure.

Further analyses showed that cellulose fibers synthesized by K. xylinus E25 in the presence of HEC were thinner compared to the fibers of control BNC membranes (Fig. 2) while there was no difference in the fibers width between the BNC-CMC and control $\mathrm{BNC}$. The difference in the size of fibers suggests that coating of cellulose microfibrils by HEC whose substituent group is larger than $-\mathrm{CH}_{2} \mathrm{OH}$, disturbed their co-crystallization, which is a prerequisite of typical BNC ribbons formation. The substituent group of HEC may shield the cellulose backbone which negatively affects the assembly of cellulose ribbons. The similar phenomenon was reported by (Zhou et al. 2009) who observed that cellulose fibrils were coated by HEC (in concentrations ranging from 0.5 to $4.0 \%$ w/v) and had a smaller lateral dimension than pure BNC fibrils. Although the concentration of CMC and HEC in the culture medium was the same, crystallization of cellulose synthesized by K. xylinus E25 in the presence of $0.5 \% \mathrm{w} / \mathrm{v}$ CMC was apparently unaffected and therefore the fibers produced in the presence and absence of this polymer had nearly the same width. According to Haigler et al. (1982), substitution of 4, 7, or 12 carboxyls per 10 glucose molecules does not

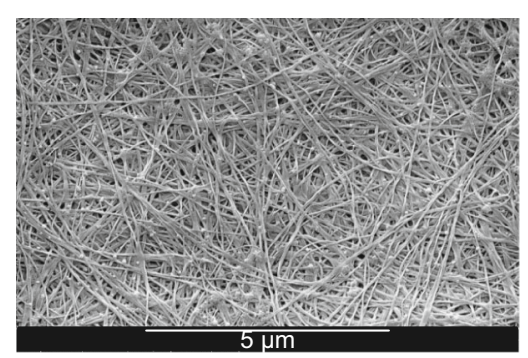

(a)

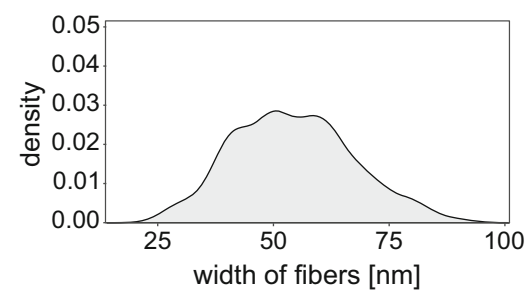

(d)

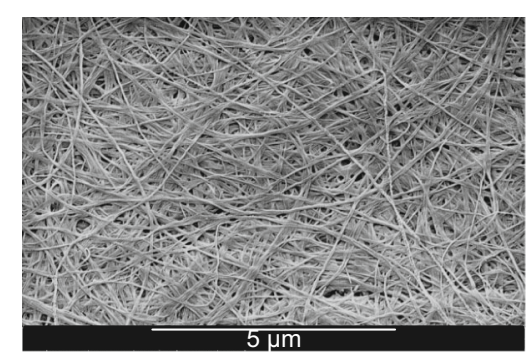

(b)

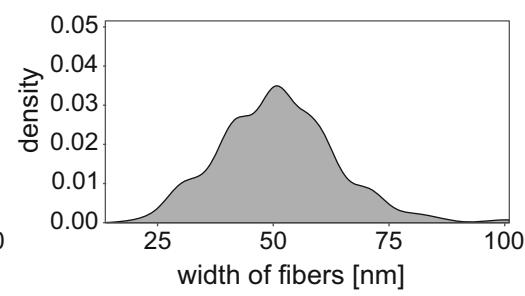

(e)

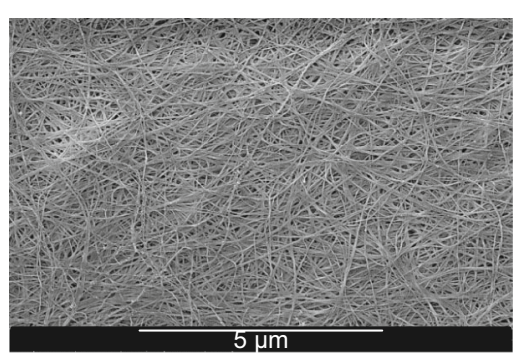

(c)

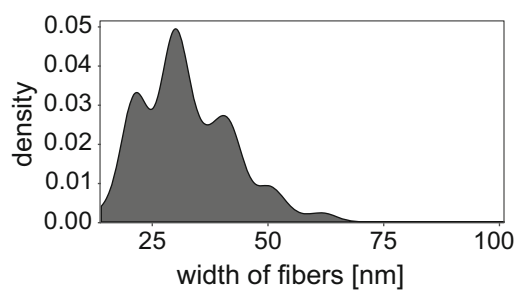

(f)
Fig. 2 Scanning electron microscope images of cellulose fibers synthesized by K. xylinus E25: a native BNC, b BNC-CMC and c BNC-HEC, and the probability density function of fibers width in $\mathbf{d}$ BNC, $\mathbf{e}$ BNC-CMC and $\mathbf{f}$ BNC-HEC; the images a-c were recorded at the magnification of $40,000 \times($ bar $-5 \mu \mathrm{m})$, and the plots of the probability density function of fibers width were prepared on the basis of at least 300 measurements for each sample 
shield the glucan backbone of CMC and this polymer may associate closely with the bacterial cellulose. However, CMC strongly affects the assembly of ribbons and therefore, the structure of the BNCCMC composite was the loosest.

This result cannot be compared with findings of other authors because of the lack of detailed literature data showing the distribution of fibers width. Cheng et al. (2009) observed that as CMC concentration in the culture medium increased from 0.2 to $0.5 \% \mathrm{w} / \mathrm{v}$, the width of cellulose fibers, which was around 15-30 nm, decreased slightly. The other authors observed incorporation of CMC (1-5\% w/v) into the BNC matrix (Dayal and Catchmark 2016) or changes in the microstructure, e.g. parallel oriented fibrils in the BNC-CMC composites (Ben-Hayyim and Ohad 1965) but none of them plotted the probability density function of fibers width.

\section{XRD analysis}

The XRD analysis has been used to evaluate the CI of BNC and BNC-based composites. The diffraction patterns of studied samples are shown in Fig. 3. The principal peaks are at $2 \theta$ values of $\sim 14.7^{\circ}, \sim 17.3^{\circ}$ and $\sim 22.9^{\circ}$. These peaks correlate with $(1-10)$, (110) and (200) crystal lattice planes respectively, which can be assigned to typical cellulose I crystalline structure (French 2014). The diffractograms of BCNbased composites also show a sharp peak at an angle of $2 \theta \sim 29.5^{\circ}$, which can be attributed to the strongly adsorbed phosphates that were contained in the culture media (ICDD PDF-2 No. 00-010-0190).

The values of crystallinity index, which were determined by the XRD method for BNC and the two BNC-based composites, are presented in Table 1. The obtained results show that incorporation of both CMC and HEC affected the process of bacterial cellulose crystallization and therefore the values of crystallinity index of the both composites are lower compared to the pure BNC. The lowest value of the crystallinity index of BNC-CMC was consistent with its loosest structure. The decrease in the crystallinity of BNC was also reported by Cheng et al. (2009) who supplemented the culture medium for Acetobacter xylinum with different polysaccharides, including CMC (the decrease from $85 \%$ to $80 \%$ for $0.8 \% \mathrm{CMC}$ ).

\section{FTIR analysis}

The FTIR spectra of BNC, BNC-CMC and BNC-HEC are presented in Fig. 4. Samples were scanned over the range of $4000-650 \mathrm{~cm}^{-1}$ to observe the effect of the in situ modification of BNC with CMC and HEC.

The FTIR spectra of BNC, BNC-CMC and BNCHEC contain the peaks characteristic of cellulose such as the absorption bands at approximately $3344 \mathrm{~cm}^{-1}$ and $2919 \mathrm{~cm}^{-1}$, which correspond to -OH stretching and $-\mathrm{CH}$ stretching, respectively (Mohammadkazemi 2015; Du et al. 2018). In case of HEC and CMC, the peak at $3344 \mathrm{~cm}^{-1}$ was broad and slightly shifted due to overlapping of a few absorption bands from intra-
Fig. 3 XRD diffraction patterns of $\mathrm{BNC}, \mathrm{BNC}$ $\mathrm{CMC}$ and $\mathrm{BNC}-\mathrm{HEC}$

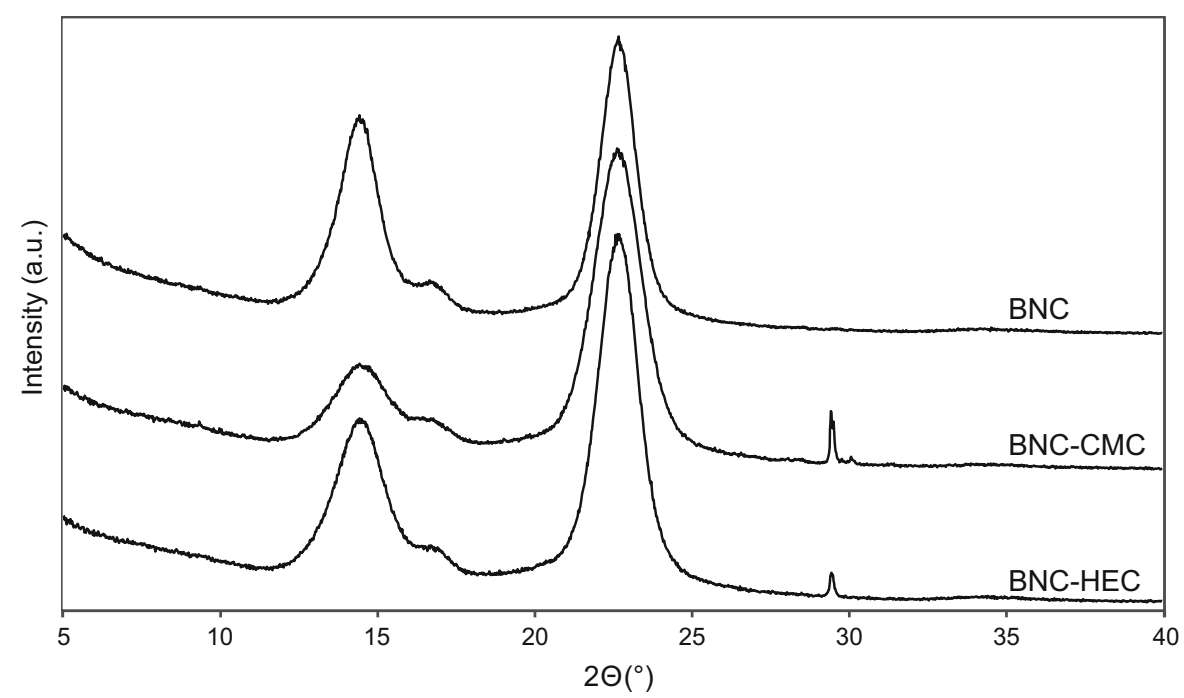


Table 1 Crystallinity index for BNC, BNC-CMC and BNCHEC

\begin{tabular}{ll}
\hline Sample & CI $(\%)$ \\
\hline BNC & 92.9 \\
BNC-HEC & 90.4 \\
BNC-CMC & 88.6 \\
\hline
\end{tabular}

$1590 \mathrm{~cm}^{-1}$ was associated with $\mathrm{COO}^{-}$in case of CMC (Hessler and Klemm 2009). The spectrum of BNC-CMC contained a broad peak at that region, due to overlapping of the band from both BNC and CMC. The occurrence of the hydroxyethyl group in the cellulose derivative, such as HEC, can be seen as a shift of C-O-C stretching vibration peak from 900 to $887 \mathrm{~cm}^{-1}$ (Gorgieva and Kokol 2011). In BNC-HEC

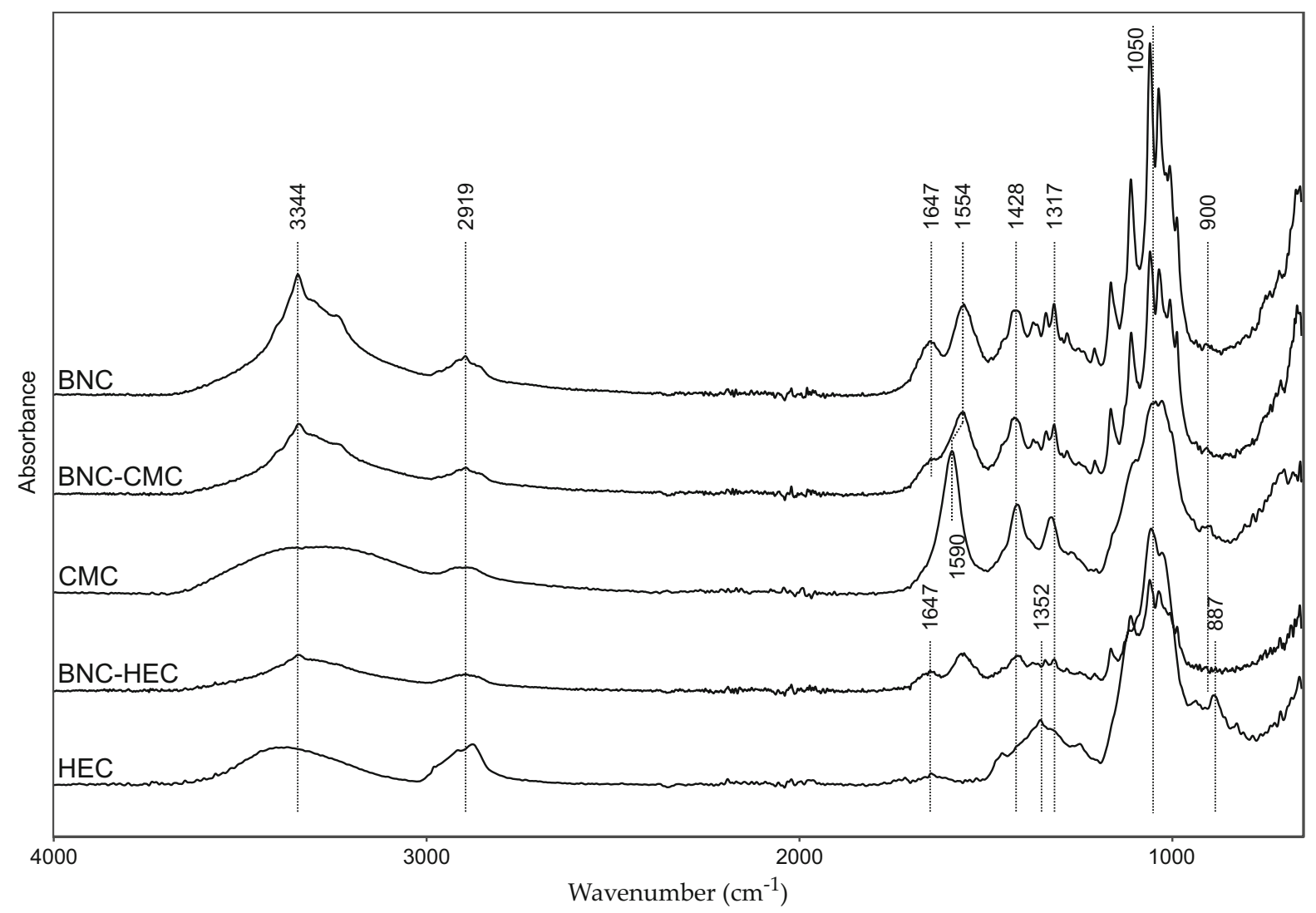

Fig. 4 FTIR spectra of BNC and BNC-based composites

and intermolecular hydrogen bonds, such as $0(2) \mathrm{H} . . \mathrm{O}(6), 0(3) \mathrm{H} \ldots \mathrm{O}(5)$ and $0(6) \mathrm{H} . . .0(3)$ (Gorgieva and Kokol 2011). The peaks at around 1050 and $1317 \mathrm{~cm}^{-1}$ were assigned to the $\mathrm{C}-\mathrm{O}$ symmetric stretching and $\mathrm{CH}_{2}$ wagging, respectively (Mohammadkazemi 2015), while absorption band at $1428 \mathrm{~cm}^{-1}$ corresponded to symmetrical bending of $\mathrm{CH}_{2}$ group (Jia et al. 2017). The appearance of the peak at $1647 \mathrm{~cm}^{-1}$ corresponded to the bending vibration of hydroxyl groups for BNC and HEC (Gorgieva and Kokol 2011), while the band at that band is visible at both these wavelengths. The wide peak at $1352 \mathrm{~cm}^{-1}$ is assigned to $\mathrm{C}-\mathrm{OH}$ in plane stretching of HEC and therefore in the BNC-HEC composite we can observe the slight deformation between 1200 and $1400 \mathrm{~cm}^{-1}$. 
Characterization of BNC, BNC-CMC and BNC-

HEC composites with glycerol

\section{The dependence of free swell absorptive capacity on glycerol concentration}

Cellulose membranes with an enhanced liquid absorption capacity may be used for healing of wounds characterized by the massive secretion of exudates because they will be able to absorb an excess of fluids, and isolate the wounds from external conditions. The parameter which specifies the highest amount of liquid, which may be absorbed by the wound dressing, is the free swell absorptive capacity (ISO 13726 standard). The dependence of this parameter on glycerol concentration, which was used for plasticizing of the BNC, BNC-CMC and BNC-HEC membranes, and varied from 0.1 to $10 \% \mathrm{v} / \mathrm{v}$, was determined according to the ISO 13726 standard. The amounts of artificial exudates absorbed by the membranes were measured after $30 \mathrm{~min}$ (Fig. 5a) and 24 h (Fig. 5b).

The results presented in Fig. 5 demonstrate that both the glycerol-plasticized and glycerol-free BNCCMC absorbed much more artificial exudate than the BNC-HEC and BNC. This difference may be ascribed to the fact that the BNC-CMC had the looser structure than BNC and BNC-HEC. The BNC-HEC, which was characterized by the thinnest fibers (the greater specific surface area comparing to BNC and BNCCMC), absorbed significantly more artificial exudate than BNC, but significantly less than BNC-CMC. The amounts of artificial exudate absorbed within $30 \mathrm{~min}$ were the greatest (above $10 \mathrm{~g}$ per $1 \mathrm{~g}$ dry weight) for the glycerol concentrations ranging from 0.5 to $2.5 \%$ $\mathrm{v} / \mathrm{v}$. After $24 \mathrm{~h}$, the maximum absorption of artificial exudate (of $19 \mathrm{~g}$ per $1 \mathrm{~g}$ dry weight) was observed at the glycerol concentration of $2.5 \% \mathrm{v} / \mathrm{v}$. Also at the glycerol concentrations of 0.5 and $1.0 \%(\mathrm{v} / \mathrm{v})$ the uptake of the exudate was relatively high (of 16 and $17 \mathrm{~g}$ per $1 \mathrm{~g}$ dry weight). At the higher (5 and $10 \%$ $\mathrm{v} / \mathrm{v})$ and lower $(0.05-0.25 \% \mathrm{v} / \mathrm{v})$ glycerol concentrations, the liquid uptake was below $14 \mathrm{~g} / \mathrm{g}$ dry weight. The data presented in the Fig. 5 demonstrate that the absorption of the artificial exudate was slower at the glycerol concentrations ranging from 1 to $5 \%$, comparing to the concentrations below $1 \% \mathrm{v} / \mathrm{v}$. For instance, within $30 \mathrm{~min}$ BNC-CMC and BNC-HEC plasticized with $2.5 \%$ glycerol adsorbed only $54 \%$ and
$56 \%$ of the artificial exudate adsorbed within $24 \mathrm{~h}$, respectively. At the glycerol concentrations below $1 \%$, the liquid adsorbed within 30 min accounted for $60-85 \%$ of the amount adsorbed within $24 \mathrm{~h}$. These data demonstrate that plasticization of BNC, BNC$\mathrm{CMC}$ and $\mathrm{BNC}-\mathrm{HEC}$ with glycerol extends the time of exudates absorption by the dressing.

The dependence of rehydration capacity on the glycerol concentration used to plasticize the nanocomposites

Bacterial cellulose is an excellent dressing of various wounds, including burns. One of most important parameters, deciding of the utility of BNC is its high water holding capacity, reaching up to $99 \%$ wet pellicle mass (Ul-Islam et al. 2012). In the contact with skin, BNC creates an ideal environment ensuring regeneration of cells of soft tissues (Czaja et al. 2007). The proposed modification of $\mathrm{BNC}$ and its composites with HEC and CMC is based on plasticization with glycerol, which leads to the improvement of certain properties comparing to the native BNC. First of all, glycerol ensures the rehydration of dehydrated composites after the long-term storage. The storage of dehydrated bacterial cellulose membranes is more convenient than the storage of never-dried membranes. Furthermore, glycerol is one of antimicrobial agents (Sun et al.2018), which additionally protect the wound from contamination. The effect of glycerol concentration in the aqueous solutions used to plasticize the BNC, BNC-CMC and BNC-HEC nanocomposites on the rehydration capacity after dehydration of the plasticized membranes is shown in Fig. 6. It is well known that the unique hydrogel microstructure of native BNC cannot be recovered after dehydration, and also our investigations confirmed this conclusion. Therefore, determination of the parameter such as rehydration capacity, which is the ratio of water absorbed after dehydration to the water content in the never-dried membrane, is very important for the characterization of wound dressings. The values of rehydration capacity of the control BNC equaled $2.1 \%$ and $2.4 \%$ after $30 \mathrm{~min}$ and $24 \mathrm{~h}$, respectively. The BNC-HEC and BNC-CMC composites were more prone to rehydration as they bound 4.6 and $9.1 \%$ water after $24 \mathrm{~h}$. Thus, the dehydrated BNC, BNC-CMC and BNC-HEC will not be able to ensure the stable, moist environment which is required in case of the modern 


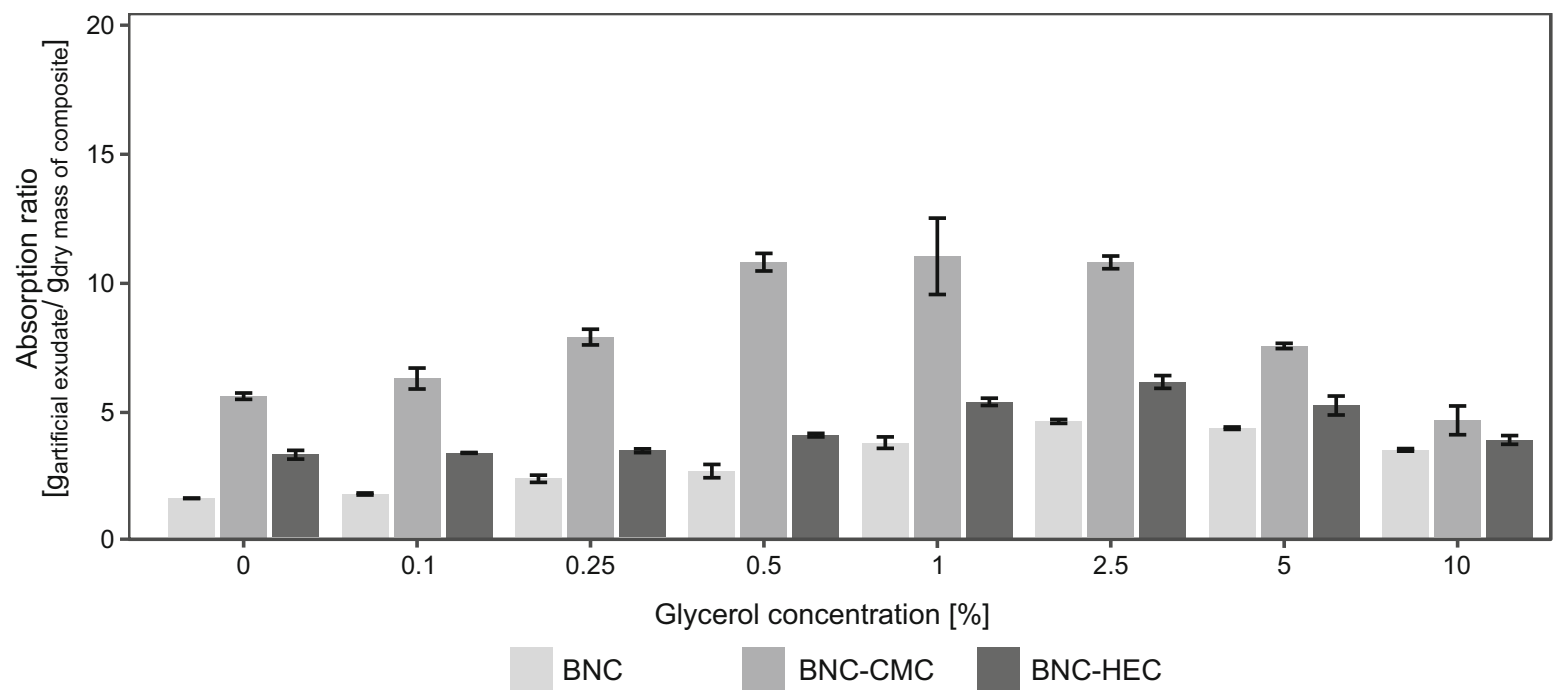

(a)

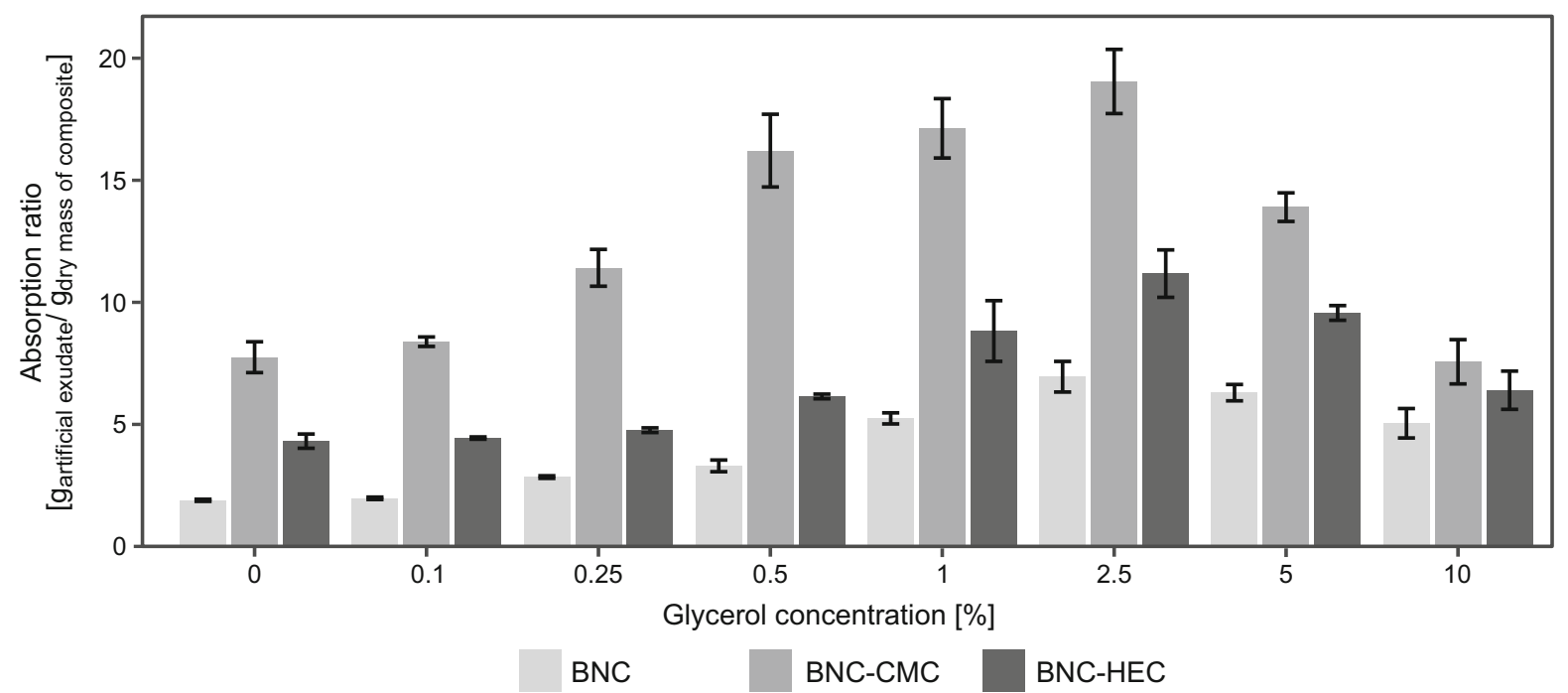

(b)

Fig. 5 The dependence of free swell absorptive capacity of BNC, BNC-CMC and BNC-HEC on glycerol concentration in the aqueous solution used for plasticizing, $\mathbf{a}$ after $30 \mathrm{~min}$ and $\mathbf{b}$ after $24 \mathrm{~h}$

wound dressings. The data presented in Fig. 6 demonstrate that the rehydration capacity was strongly affected by the concentration of aqueous glycerol solution used for plasticizing, and increased with this concentration. Furthermore, irrespective of the glycerol concentration and duration of rehydration (30 min or $24 \mathrm{~h}$ ), the BNC-CMC nanocomposites outperformed the other membranes with regard to the rehydration capacity, which decreased in the order BNC-CMC $>$ BNC-HEC $>$ BNC. The nanocompos- ites plasticized with $10 \%$ aqueous glycerol were characterized by the greatest rehydration capacity. This parameter increased with the glycerol concentration and for $10 \%$ glycerol was nearly 10 -fold greater than for $0.1 \%$ glycerol.

As shown in Fig. 6b, within $24 \mathrm{~h}$ the BNC-CMC, BNC-HEC and BNC plasticized with $10 \%$ glycerol and dehydrated were capable of binding of around 97, 75 and $61 \%$ of the initial water content, respectively. When glycerol concentration was $2.5 \% \mathrm{v} / \mathrm{v}$, the 


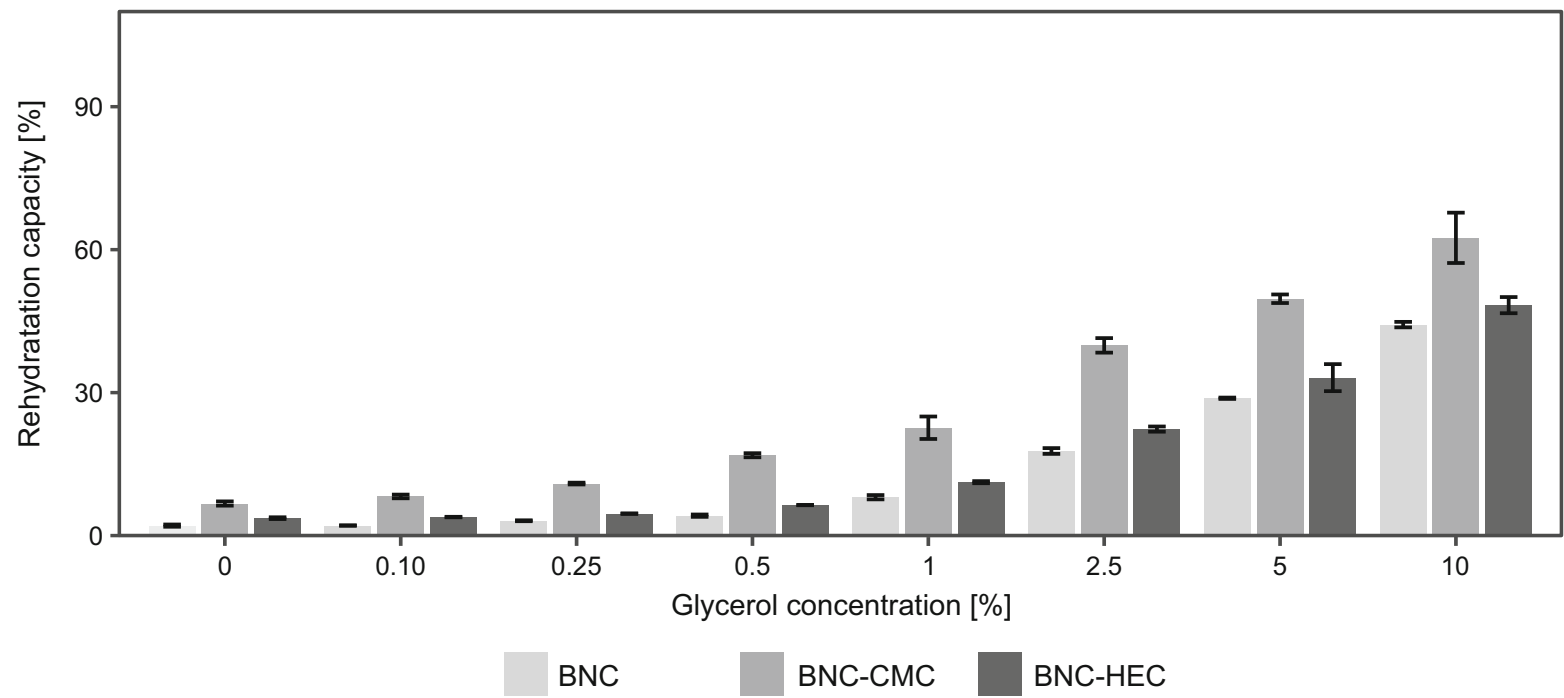

(a)

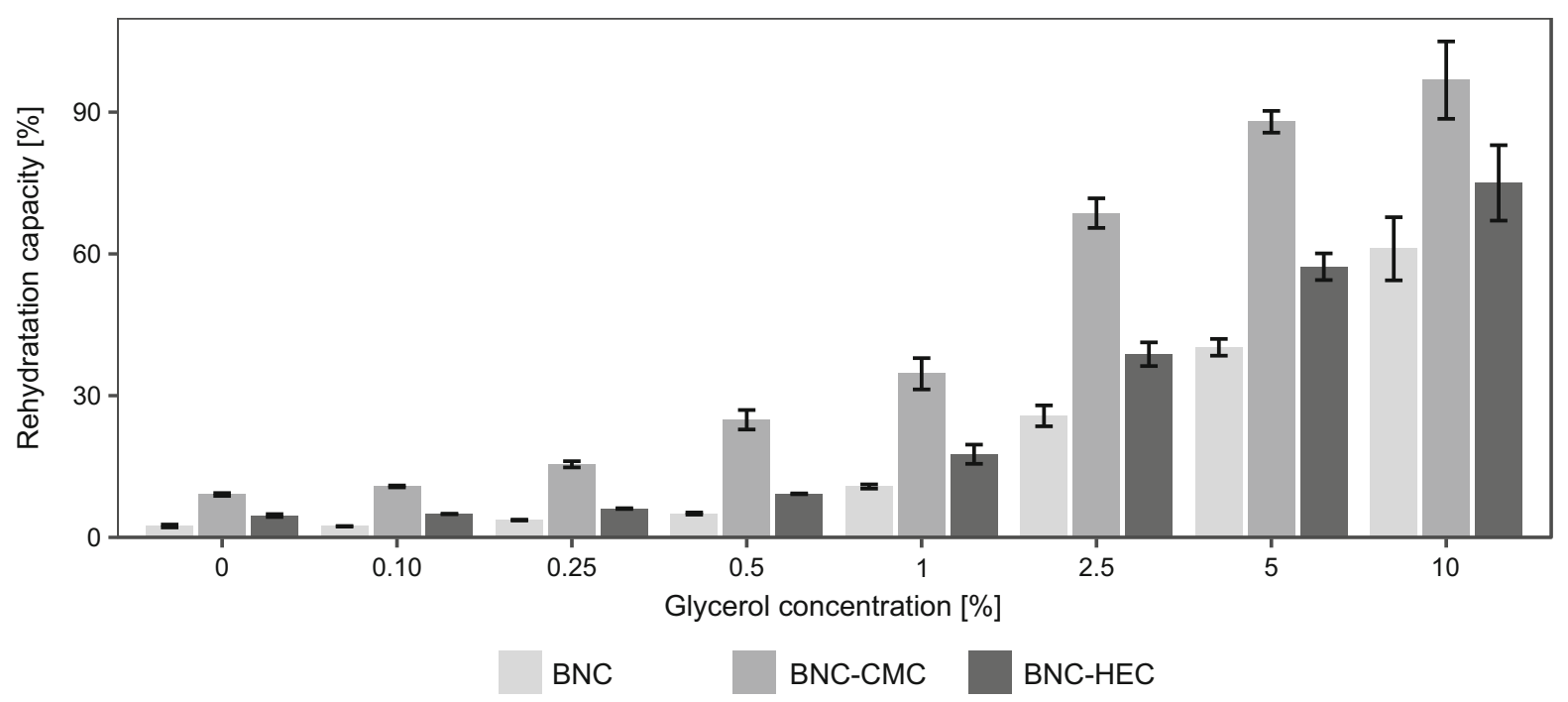

(b)

Fig. 6 The dependence of rehydration capacity of plasticized and dehydrated BNC, BNC-HEC and BNC-CMC on aqueous glycerol concentration, after a $30 \mathrm{~min}$ and $\mathbf{b} 24 \mathrm{~h}$

rehydration capacity was also relatively high, of around 69, 39 and $26 \%$ of the initial amount of absorbed water, for BNC-CMC, BNC-HEC and BNC, respectively. Further decrease in glycerol concentration reduced the rehydration capacity below $18 \%$ in case of BNC and BNC-HEC, and below 35\% for BNC-CMC.

Taking into consideration the results presented in the Figs. 5, 6, we decided to subject to further investigations (tensile strength measurements and keratinocytes viability study) only the composites plasticized with either 2.5 or $10 \% \mathrm{v} / \mathrm{v}$ glycerol owing to the highest free swell absorptive capacity and rehydration capacity, respectively. The results suggest that the application of these nanocomposites as wound dressings may delay the necessity of replacement of the used dressing with the fresh one. 


\section{Tensile strength}

Wound dressings should possess sufficiently high mechanical strength to maintain integrity during the wound healing process and enable easy application and removal. Bacterial nanocellulose is known to be not only a nearly ideal wound dressing but also an excellent matrix for production of novel wound dressings with tailored features (Bielecki et al. 2013). The data presented in Table 2 provide evidence that the in situ modification of BNC with either CMC or HEC affected mechanical properties of the polymer. The HEC-composite was characterized by the reduced tensile strength at break (around $38 \mathrm{~N}$ versus around $69 \mathrm{~N}$ for the control BNC) and lower Young's modulus (around 9.5 MPa versus around 11.3 MPa) while the Young's modulus of the CMC-composite was higher (around 13.6 MPa) despite the lower tensile strength at break (around $27.8 \mathrm{~N}$ ). According to literature, the values of Young's modulus for BNC vary in the range 1-10 MPa while the tensile strength of BNC-based composites depends on the additives and their content (Dayal and Catchmark 2016). When interactions with the polysaccharide added to the culture medium negatively affect binding of cellulose molecules during BNC synthesis, the network formed by the fibrils is weaker. The values of the strain $(\varepsilon)$, calculated as $\Delta \mathrm{L} / \mathrm{L}_{0}$, were nearly twice smaller in case of the two composites comparing to the control BNC (of around 17.4, 18.3 and $36 \%$ for BNC-HEC, BNC-
$\mathrm{CMC}$ and $\mathrm{BNC}$, respectively). Thus the control BNC was characterized not only by the greater tensile strength at break but also by the around twice greater exerted extension from starting point comparing to the two composites.

Also plasticizing of BNC, BNC-CMC and BNCHEC with glycerol, which reduces the strength of hydrogen bonds between adjacent cellulose chains, altered the tensile strength of the membranes. The influence of glycerol concentration of $2.5 \% \mathrm{v} / \mathrm{v}$, which corresponded to the highest liquid uptake by all the nanocomposites was compared with the effect of the highest glycerol concentration studied, of $10.0 \% \mathrm{v} / \mathrm{v}$. The highest increase in the values of tensile strength at break (from around 27.8 $\mathrm{N}$ to $152.2 \mathrm{~N}$ ) and Young's modulus (from around 13.6 MPa to 290.3 MPa) was observed in case of the BNC-CMC composite plasticized with $2.5 \% \mathrm{v} / \mathrm{v}$ glycerol. Also plasticizing with $10 \% \mathrm{v} / \mathrm{v}$ glycerol had the positive effect on these parameters but it was much weaker. Also in case of BNC-HEC and BNC the significant increase in the values of tensile strength at break (from around $38.1 \mathrm{~N}$ to $101.1 \mathrm{~N}$, and from $68.9 \mathrm{~N}$ to $109.7 \mathrm{~N}$, respectively) and Young's modulus (from around $9.5 \mathrm{MPa}$ to 107.1 MPa and from around 11.3 MPa to 203.3, respectively) was observed after plasticizing with $2.5 \% \mathrm{v} / \mathrm{v}$ glycerol. The impact of $10 \% \mathrm{v} / \mathrm{v}$ glycerol on these two parameters was weaker in most cases but in case of the control BNC the tensile strength at break was increased to around $110.8 \mathrm{~N}$. Interestingly, the

Table 2 The dependence of mechanical properties of BNC, BNC-CMC and BNC-HEC membranes on plasticizing with either 2.5\% or $10 \%(\mathrm{v} / \mathrm{v})$ aqueous glycerol (means \pm standard deviations)

\begin{tabular}{lccccr}
\hline Sample & cross-sectional area $\left(\mathrm{mm}^{2}\right)$ & Fmax $(\mathrm{N})$ & Stress $\sigma(\mathrm{MPa})$ & Young's modulus $\mathrm{E}_{\mathrm{M}}(\mathrm{MPa})$ & Strain $\varepsilon(\%)$ \\
\hline BNC & & & & & \\
Water & $22.47 \pm 1.32$ & $68.99 \pm 6.00$ & $3.08 \pm 0.30$ & $11.31 \pm 1.64$ & $36.02 \pm 4.02$ \\
$2.5 \%$ glycerol & $3.88 \pm 0.05$ & $109.72 \pm 10.95$ & $28.27 \pm 2.82$ & $203.30 \pm 26.52$ & $16.36 \pm 1.38$ \\
$10 \%$ glycerol & $6.00 \pm 0.04$ & $110.75 \pm 2.34$ & $18.46 \pm 0.52$ & $76.59 \pm 4.08$ & $28.13 \pm 2.44$ \\
BNC-HEC & & & & & \\
Water & $20.57 \pm 1.20$ & $38.08 \pm 1.88$ & $1.34 \pm 0.27$ & $9.48 \pm 1.79$ & $17.43 \pm 0.72$ \\
$2.5 \%$ glycerol & $3.90 \pm 0.04$ & $101.14 \pm 4.84$ & $25.90 \pm 1.04$ & $107.11 \pm 17.38$ & $24.93 \pm 2.67$ \\
$10 \%$ glycerol & $10.36 \pm 1.16$ & $54.34 \pm 0.91$ & $5.30 \pm 0.68$ & $27.36 \pm 3.41$ & $27.35 \pm 3.50$ \\
BNC-CMC & & & & & $18.25 \pm 1.10$ \\
Water & $19.36 \pm 1.33$ & $27.80 \pm 5.95$ & $1.98 \pm 0.21$ & $13.59 \pm 1.36$ & $16.17 \pm 2.14$ \\
$2.5 \%$ glycerol & $3.96 \pm 0.05$ & $152.23 \pm 6.18$ & $38.43 \pm 1.69$ & $290.31 \pm 41.74$ & $50.05 \pm 2.69$ \\
$10 \%$ glycerol & $13.49 \pm 0.89$ & $43.10 \pm 3.34$ & $3.21 \pm 0.35$ & $20.16 \pm 1.47$ & \\
\hline
\end{tabular}


values of strain $(\varepsilon)$ were significantly greater after plasticizing with $10 \% \mathrm{v} / \mathrm{v}$ glycerol comparing to $2.5 \%$ $\mathrm{v} / \mathrm{v}$ glycerol. Thus the exerted extension from starting point was significantly greater in the first case.

Noteworthy, plasticizing with both $2.5 \%$ and $10 \%$ $\mathrm{v} / \mathrm{v}$ glycerol significantly decreased the cross-sectional area (A) of BNC, BNC-CMC and BNC-HEC that along with the significantly greater values of the tensile strength at break $(\mathrm{F})$ caused that the values of stress $(\delta)$, calculated as F/A were also significantly greater.

As it was mentioned above also other authors reported the impact of $\mathrm{BNC}$ modifications on the tensile strength of BNC-based composites. Dependently on the bacterial producer and concentration of the modifying agents, either an increase or decrease in the tensile modulus values has been reported (Cai and Kim 2010; Cheng et al. 2009; Dayal and Catchmark 2016; Godinho et al. 2016; Zhou et al. 2009).

Reassuming, plasticizing of BNC, BNC-CMC and BNC-HEC with $2.5 \% \mathrm{v} / \mathrm{v}$ glycerol enabled to produce mechanically durable nanocomposites that are characterized by the high free swell absorptive capacity and rehydration capacity. Also the enhanced flexibility of these membranes make them potential wound dressing materials.

The effect of plasticized nanocomposites on keratinocytes viability

Cytotoxicity testing is a primary and crucial step that can decide of the fate of a health-related product for clinical application. To estimate the influence of the long-term contact of glycerol-plasticized BNC-based wound dressings on the viability of keratinocytes, we decided to determine the dependence of the latter parameter not only on glycerol concentration in the wound dressing but also on the polyol level in the culture medium used for cultivation of these cells. According to literature, different cells showed various sensitivity towards glycerol. For instance, in case of $\mathrm{CHO}$ (Chinese hamster ovary) cells line even $0.1 \%$ (v/ v) glycerol negatively affected cell viability (Rodas et al. 2008) while in case of spleen cells isolated from BALB/c mouse, $10 \%$ glycerol reduced cell viability by only $10 \%$, comparing to the control (Vaitkuviene et al. 2009). The impact of the glycerol content in the culture medium used for $24 \mathrm{~h}$ cultivation of keratinocytes on the viability of these cells is presented in
Fig. 7a. The concentrations ranging from 0.5 to $2.5 \%$ $\mathrm{v} / \mathrm{v}$ ensured the relatively high viability, of at least $80 \%$, comparing to the glycerol-free control. Further increase in the glycerol concentration, to 5 and $10 \%$ $\mathrm{v} / \mathrm{v}$, significantly reduced the viability, to around $50 \%$ and $10 \%$, respectively. These results suggest that contact of keratinocytes with the BNC-based wound dressings plasticized with $0.5-2.5 \%$ glycerol may not negatively affect these cells. Thus, the BNC-CMC nanocomposites plasticized with $2.5 \%$ v/v glycerol, which are characterized by very attractive liquid sorption and tensile properties, may be regarded potential wound dressings.

To verify the latter conclusion, we applied both the direct contact and the extract dilution methods. $\mathrm{HaCaT}$ cells were seeded on the surface of the BNC, BNCCMC and BNC-HEC scaffolds plasticized with either $2.5 \%$ or $10 \% \mathrm{v} / \mathrm{v}$ glycerol (or glycerol-free), and incubated at $37{ }^{\circ} \mathrm{C}$ in a humidified atmosphere for $24 \mathrm{~h}$. Like in the former experiment, the viability of cells was determined using the PrestoBlue ${ }^{\circledR}$ Cell Viability Reagent. It was expressed as a percent of the viability of the cells growing on the control commercial plastic scaffold. The comparison of the growth of the HaCaT cells on the latter scaffold and the glycerolfree BNC, BNC-CMC and BNC-HEC scaffolds showed that these three BNC-based scaffolds may be used for cultivation of keratinocytes (Fig. 7d). Furthermore, this experiment showed that the $24 \mathrm{~h}$ contact with $2.5 \% \mathrm{v} / \mathrm{v}$ aqueous glycerol solution was completely safe for the keratinocytes while $10 \% \mathrm{v} / \mathrm{v}$ glycerol significantly reduced their viability. The negative impact of $10 \% \mathrm{v} / \mathrm{v}$ glycerol was the weakest in case of the BCN-HEC nanocomposite.

To determine the effect of glycerol-plasticized wound coverings on the viability of keratinocytes, the $\mathrm{HaCaT}$ cells were cultivated on plastic surface for $24 \mathrm{~h}$ in the culture medium, which was then removed, and the cells were covered by the scaffolds plasticized with either $2.5 \%$ or $10 \% \mathrm{v} / \mathrm{v}$ glycerol (or glycerol-free controls). After $24 \mathrm{~h}$ incubation of the cells under the scaffolds, the latter were removed and the viability of cells was determined using the PrestoBlue ${ }^{\circledR}$ Cell Viability Reagent. It was expressed as a percent of the viability of the cells incubated on the plastic surface in DMEM medium. The results presented in Fig. 7c provide evidence that also in this case, the scaffolds soaked in $2.5 \% \mathrm{v} / \mathrm{v}$ aqueous glycerol solution had no negative impact on the viability of keratinocytes while 


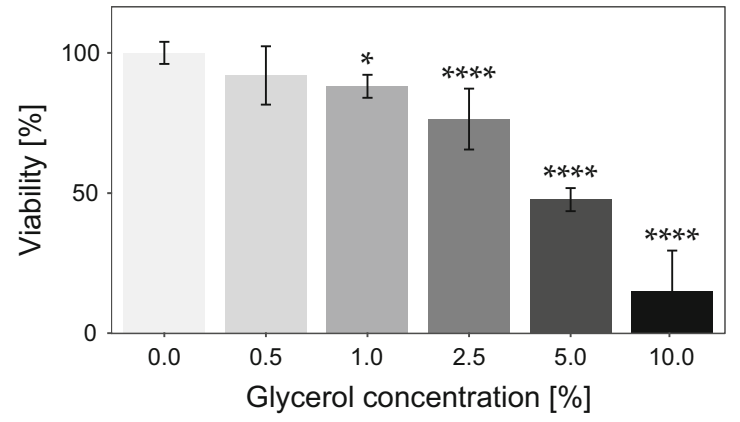

(a)

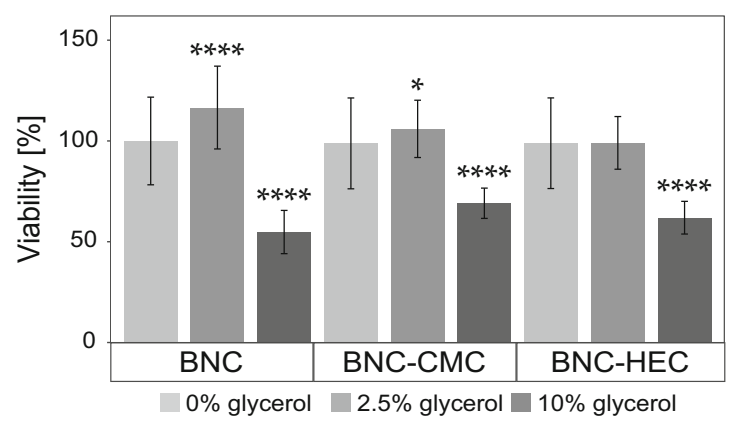

(c)

Fig. 7 Viability of HaCaT keratinocytes in different conditions after $24 \mathrm{~h}$ of incubation: a the dependence of $\mathrm{HaCaT}$ viability on the concentration of glycerol in the culture medium, $\mathbf{b}$ the effect of glycerol concentration used for plasticizing of BNC, BNCCMC and BNC-HEC on the viability of keratinocytes cultivated on the surface of the scaffolds, $\mathrm{c}$ the effect of glycerol concentration used for plasticizing of BNC, BNC-CMC and $\mathrm{BNC}-\mathrm{HEC}$ on the viability of keratinocytes cultivated under the

the contact with $10 \%$ aqueous glycerol solution significantly reduced the viability of these cells.

BNC, BNC-CMC and BNC-HEC scaffolds plasticized with glycerol may release leachable products during the extraction. Therefore, the cytotoxicity test based on the extraction method was performed. Subconfluent $\mathrm{HaCaT}$ cells were exposed for $24 \mathrm{~h}$ to pure and diluted extracts (100, 50 and 25\%) from the scaffolds. It was observed that the extract media had a weak impact on the cell viability (Fig. 7b) because it was reduced by less than $15 \%$ in the presence of $100 \%$ extracts from the scaffolds. This effect was equivalent to that of $0.5-1 \%$ pure glycerol added to the culture medium what may suggest that the larger part of glycerol was associated with the scaffolds, which were plasticized with $10 \%$ glycerol, and only a small part was released to the extract. Reassuming, the series of experiments aiming at determination of the influence

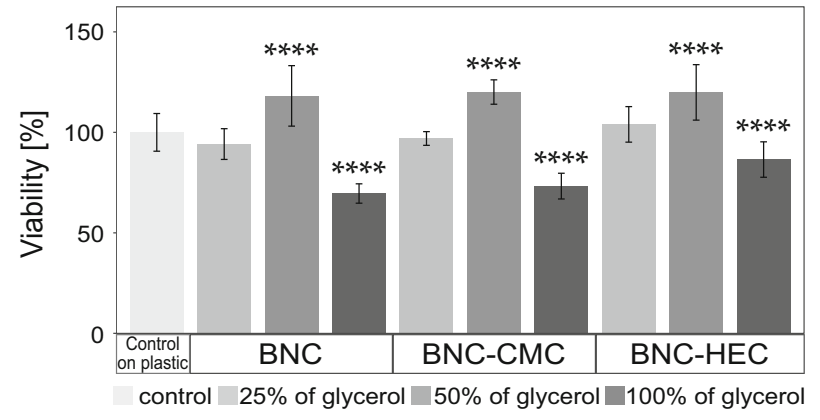

(b)

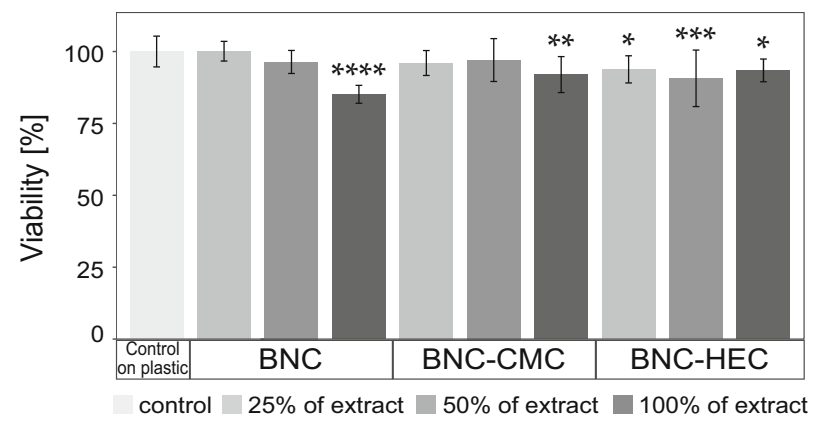

(d)

scaffolds, d the dependence of $\mathrm{HaCaT}$ cells viability on the concentration of scaffold extracts; the viable cell number was assayed with PrestoBlue ${ }^{\circledR}$ Cell Viability Reagent; the data are presented as the mean \pm SD from at least three independent experiments; multiple comparison was assessed by One-way ANOVA; statistical significance shown as: $* p<0.05$, $* * p<0.01, * * * p<0.001, * * * * p<0.0001$ in comparison to control HaCaT cells growth

of the two selected glycerol concentrations (2.5 and $10 \% \mathrm{v} / \mathrm{v}$ ) on the viability of the $\mathrm{HaCaT}$ cells, provided evidence that the lower of these concentrations is safe for the cells. Thus, the BNC-based nanocomposites, plasticized with $2.5 \% \mathrm{v} / \mathrm{v}$ aqueous glycerol solution and dehydrated, may be used as wound dressings. These nanocomposites outperform traditional BNC dressings because they may be dehydrated without any negative effect on the flexibility and liquid holding capacity. Besides, the storage of the dehydrated, glycerol-plasticized BNC-based composites is much more convenient than the storage of never-dried BNC membranes.

The surprising phenomenon of elevated cell viability caused by the growth on BNC, BNC-CMC and BNC-HEC scaffolds plasticized with $2.5 \%$ glycerol is contradictory to the results of the cytotoxicity test, in which pure glycerol was added to the culture medium 
because even the lowest glycerol concentration, of $0.5 \%$, caused a decrease in the cell viability. However, the cumulative effect of $2.5 \%$ glycerol and neutral BNC, BNC-CMC and BNC-HEC matrices on keratinocytes was positive. The similar phenomenon was reported in literature. For instance, the cytotoxic compound like $\mathrm{ZnCl}_{2}$ used along with the neutral 3-aminopropyl triethoxysilane enhanced cell viability (Chun et al. 2017). This is difficult to compare the results of our study with findings of other authors because the glycerol-induced toxicity has not been reported so far for mammalian cells exposed to BNC scaffolds. However, cytoprotective properties of carboxymethylcellulose against polyhexamethylene biguanides added to bacteria were reported (Vehige et al. 2003). Therefore, we may only assume that the BNC composites studied have the similar cytoprotective properties, and further investigations in this field are necessary.

\section{Conclusions}

The presented combination of in situ and ex situ modifications of bacterial cellulose synthesized by $K$. xylinus E25 under stationary conditions, enabled to produce nanocomposites that may replace traditional BNC dressings. The glycerol-plasticized BNC, BNC$\mathrm{CMC}$ and BNC-HEC membranes were flexible after drying, and absorbed large amounts of artificial exudate and water after rehydration. The impact of plasticized BNC, BNC-CMC and BNC-HEC on the viability of $\mathrm{HaCaT}$ keratinocytes was positive at glycerol concentrations up to $2.5 \%(\mathrm{v} / \mathrm{v})$. BNC-CMC treated with $2.5 \% \mathrm{v} / \mathrm{v}$ aqueous glycerol was characterized by the greatest free swell absorptive capacity (up to $19 \mathrm{~g}$ artificial exudate/g dry weight in $24 \mathrm{~h}$ ), and the highest values of tensile strength at break (around $152.2 \mathrm{~N}$ ) and Young's modulus (around 290.3 MPa). These properties suggest that the latter nanocomposite may be applied as a convenient, mechanically durable and safe wound dressing.

\footnotetext{
Acknowledgments The authors would like to thank Dr. Przemysław Rytczak for comments related to conceptualization of this study and for material support of the fibroblast viability evaluation. We are indebted to Jolanta Płoszyńska for technical support and to Marcin Rosowski for his contribution to recording the SEM images.
}

\section{Compliance with ethical standards}

Conflicts of interest The authors declare no conflict of interest.

Open Access This article is distributed under the terms of the Creative Commons Attribution 4.0 International License (http:// creativecommons.org/licenses/by/4.0/), which permits unrestricted use, distribution, and reproduction in any medium, provided you give appropriate credit to the original author(s) and the source, provide a link to the Creative Commons license, and indicate if changes were made.

\section{References}

Ben-Hayyim G, Ohad I (1965) Synthesis of cellulose by Acetobacter xylinum: VIII. On the formation and orientation of bacterial cellulose fibrils in the presence of acidic polysaccharides. J Cell Biol 25(2):191-207. https://doi. org/10.1083/jcb.25.2.191

Bielecki S, Krystynowicz A, Turkiewicz M, Kalinowska H (2002) Bacterial cellulose. In: Steinbuchel A (ed) Biopolymers, vol 5. Wiley-VCH, Weinheim, pp 37-90. ISBN 978-3-527-30226-0

Bielecki S, Kalinowska H, Krystynowicz A, Kubiak K, Kołodziejczyk M, de Groeve M (2013) Wound dressings and cosmetic materials from bacterial nanocellulose. In: Gama M, Gatenholm P, Klemm D (eds) Bacterial Nanocellulose. A sophisticated multifunctional material, 1st edn. CRC Press, Taylor \& Francis Group, Boca Raton, Florida, pp 157-174, ISBN 9781138073166

Budhiono A, Rosidi B, Taher H, Iguchi M (1999) Kinetic aspects of bacterial cellulose formation in nata-de-coco culture system. Carbohydr Polym 40:137-143. https://doi. org/10.1016/S0144-8617(99)00050-8

Cai Z, Kim J (2010) Bacterial cellulose/poly(ethylene glycol) composite: characterization and first evaluation of biocompatibility. Cellulose 17(1):83-91. https://doi.org/10. 1007/s10570-009-9362-5

Campano C, Balea A, Blanco A, Negro C (2016) Enhancement of the fermentation process and properties of bacterial cellulose: a review. Cellulose 23:57-91. https://doi.org/10. 1007/s10570-015-0802-0

Chen Y, Zhou X, Lin Q, Jiang D (2014) Bacterial cellulose/ gelatin composites: in situ preparation and glutaraldehyde treatment. Cellulose 21:2679-2693. https://doi.org/10. 1007/s10570-014-0272-9

Cheng KC, Catchmark JM, Demirci A (2009) Effect of different additives on bacterial cellulose production by Acetobacter xylinum and analysis of material property. Cellulose 16(6):1033-1045. https://doi.org/10.1007/s10570-0099346-5

Chun H-S, Park D, Lim SE, Jeong K-H, Park J-S, Park H-J, Kang S, Kang KS, Park H-G, An H-R, Huh YS, Lee Y-C (2017) Two zinc-aminoclays' in vitro cytotoxicity assessment in HeLa cells and in vivo embryotoxicity assay in zebrafish. Ecotoxicol Environ Saf 137:103-112. https:// doi.org/10.1016/j.ecoenv.2016.11.022 
Cielecka I, Szustak M, Gendaszewska-Darmach E, Kalinowska H, Ryngajłło M, Maniukiewicz W, Bielecki S (2018) Novel bionanocellulose/К-carrageenan composites for tissue engineering. Appl Sci 8(8):1352. https://doi.org/10. 3390/app8081352

Czaja W, Young DJ, Kawecki M, Brown RM (2007) The future prospects of microbial cellulose in biomedical applications. Biomacromol 8(1):1-12. https://doi.org/10.1021/ bm060620d

Dayal MS, Catchmark JM (2016) Mechanical and structural property analysis of bacterial cellulose composites. Carbohydr Polym 144:447-453. https://doi.org/10.1016/j. carbpol.2016.02.055

Du R, Zhao F, Peng Q, Zhou Z, Han Y (2018) Production and characterization of bacterial cellulose produced by Gluconacetobacter xylinus isolated from Chinese persimmon vinegar. Carbohydr Polym 194:200-207. https://doi.org/ 10.1016/j.carbpol.2018.04.041

Fang L, Catchmark JM (2014) Characterization of water-soluble exopolysaccharides from Gluconacetobacter xylinus and their impacts on bacterial cellulose crystallization and ribbon assembly. Cellulose 21:3965-3978. https://doi.org/ 10.1007/s10570-014-0443-8

French AD (2014) Idealized powder diffraction patterns for cellulose polymorphs. Cellulose 21:885-896. https://doi. org/10.1007/s10570-013-0030-4

Godinho JF, Berti FV, Muller D, Rambo CR, Porto LM (2016) Incorporation of Aloe vera extracts into nanocellulose during biosynthesis. Cellulose 23:545-555. https://doi.org/ 10.1007/s10570-015-0844-3

Gorgieva S, Kokol V (2011) Synthesis and application of new temperature-responsive hydrogels based on carboxymethyl and hydroxyethyl cellulose derivatives for the functional finishing of cotton knitwear. Carbohydr Polym 85:664-673. https://doi.org/10.1016/j.carbpol.2011.03. 037

Haigler CH, White AR, Brown RM Jr, Cooper KM (1982) Alteration of in vivo cellulose ribbon assembly by carboxymethylcellulose and other cellulose derivatives. J Cell Biol 94:64-69. https://doi.org/10.1083/jcb.94.1.64

Hessler N, Klemm D (2009) Alteration of bacterial nanocellulose structure by in situ modification using polyethylene glycol and carbohydrate additives. Cellulose 16:899-910. https://doi.org/10.1007/s10570-009-9301-5

Jia YY, Wang XH, Huo MM, Zhai XL, Li F, Zhong C (2017) Preparation and characterization of a novel bacterial cellulose/chitosan bio-hydrogel. Nanomater Nanotechnol 7:1-8. https://doi.org/10.1177/1847980417707172

Li Y, Jiang H, Zheng W, Gong N, Chen L, Jiang X, Yang G (2015) Bacterial cellulose-hyaluronan nanocomposite biomaterials as wound dressings for severe skin injury repair. J Mater Chem B 3:3498-3507. https://doi.org/10. 1007/s10570-018-1709-3

Lin S-P, Kung H-N, Tsai Y-S, Tseng T-N, Hsu K-D, Cheng K-C (2017) Novel dextran modified bacterial cellulose hydrogel accelerating cutaneous wound healing. Cellulose 24:4927-4937. https://doi.org/10.1007/s10570-017-1448$\mathrm{x}$

Liu K, Catchmark JM (2018) Effects of exopolysaccharides from Escherichia coli ATCC 35860 on the mechanical properties of bacterial cellulose nanocomposites. Cellulose
25:2273-2287. https://doi.org/10.1007/s10570-018-17093

Machado RTA, Meneguin AB, Sabio RM, Franco DF, Antonio SG, Gutierrez J, Tercjak A, Beretta AA, Ribeiro SJL, Lazarini SC, Lustri WR, Barud HS (2018) Komagateibacter rhaeticus grown in sugarcane molasses-supplemented culture medium as a strategy for enhancing bacterial cellulose production. Ind Crops Prod 122:637-646. https://doi.org/10.1016/j.indcrop.2018.06. 048

MacNeil S (2007) Progress and opportunities for tissue-engineered skin. Nature 445:874-880. https://doi.org/10.1038/ nature 05664

Mohammadkazemi F (2015) Surface properties of bacterial nanocellulose using spectroscopic methods and X-ray diffraction. Am J Appl Indu Chem 1(2):10-13. https://doi. org/10.11648/j.ajaic.20150102.11

Nakagaito AN, Iwamoto S, Yano H (2005) Bacterial cellulose: the ultimate nano-scalar cellulose morphology for the production of high-strength composites. Appl Phys A 80(1):93-97. https://doi.org/10.1007/s00339-004-2932-3

Park S, Baker JO, Himmel ME, Parilla PA, Johnson DK (2010) Cellulose crystallinity index: measurement techniques and their impact on interpreting cellulose performance. Biotechnol Biofuels 3:3-10. https://doi.org/10.1186/17546834-3-10

Rabiej M (2014) A hybrid immune-evolutionary strategy algorithm for the analysis of the wide-angle $\mathrm{X}$-ray diffraction curves of semicrystalline polymers. J Appl Crystallogr 47:1502-1511. https://doi.org/10.1107/S16005767140147 82

Rodas ACD, Maizato MJS, Leirner AA, Pitombo RNM, Polakiewicz B, Beppu MM, Higa OZ (2008) Cytotoxicity and genotoxicity of bovine pericardium preserved in glycerol. Artif Organs 32(4):272-276. https://doi.org/10.1111/j. 1525-1594.2008.00542.x

Sanchavanakit N, Sangrungraungroj W, Kaomongkolgit R, Banaprasert T, Pavasant P, Phisalaphong M (2006) Growth of human keratinocytes and fibroblasts on bacterial cellulose film. Biotechnol Prog 22:1194-1199. https://doi.org/ 10.1021/bp060035o

Sun Y, Meng C, Zheng Y, Xie Y, He W, Wang Y, Qiao K, Yue L (2018) The effects of two biocompatibile plasticizers on the performance of dry bacterial cellulose membrane: a comparative study. Cellulose 25:5893-5908. https://doi. org/10.1007/s10570-018-1968-z

Taokaew S, Phisalaphong M, Newby BZ (2015) Modification of bacterial cellulose with organosilanes to improve attachment and spreading of human fibroblasts. Cellulose 22:2311-2324. https://doi.org/10.1007/s10570-015-0651$\mathrm{X}$

Uhlin KI, Atalla RH, Thompson NS (1995) Influence of hemicelluloses on the aggregation patterns of bacterial cellulose. Cellulose 2:129-144. https://doi.org/10.1007/ BF00816385

Ul-Islam M, Khan T, Park J (2012) Water holding and release properties of bacterial cellulose obtained by in situ and ex situ modification. Carbohydr Polym 88:596-603. https:// doi.org/10.1016/j.carbpol.2012.01.006

Ullah H, Wahid F, Santos HA, Khan T (2016) Advances in biomedical and pharmaceutical applications of functional 
bacterial cellulose-based nanocomposites. Carbohydr Polym 150:330-352. https://doi.org/10.1016/j.carbpol. 2016.05.029

Vaitkuvienè A, Kašèta V, Ramanauskaite G, Biziulevičienė G (2009) Cytotoxicity of pharmaceutical and cosmetic gelforming polymers, preservatives and glycerol to primary murine cell cultures. Acta Med Litu 16(3-4):92-97. https:// doi.org/10.2478/v10140-009-0013-9

Vehige JG, Simmons PA, Anger C, Graham R, Tran L, Brady N (2003) Cytoprotective properties of carboxymethyl cellulose $(\mathrm{cmc})$ when used prior to wearing contact lenses treated with cationic disinfecting agents. Eye Contact Lens Sci Clin Pract 29(3):177-180. https://doi.org/10.1097/01. ICL.0000074106.82322.17

Velasquez-Riano M, Bojaca V (2017) Production of bacterial cellulose from alternative low-cost substrates. Cellulose 24:2677-2698. https://doi.org/10.1007/s10570-017-1309-7
Vieira MGA, da Silva MA, dos Santos LO (2011) Natural-based plasticizers and biopolymer films: a review. Eur Polym J 47:254-263. https://doi.org/10.1016/j.europloymj.2010. 12.011

Zhou Q, Malm E, Nilsson H, Larsson PT, Iversen T, Berglund LA, Bulone V (2009) Nanostructured biocomposites based on bacterial cellulose nanofibers compartmentalized by a soft hydroxyethylcellulose matrix coating. Soft Matter 5:4124-4130. https://doi.org/10.1039/B907838J

Publisher's Note Springer Nature remains neutral with regard to jurisdictional claims in published maps and institutional affiliations. 